\title{
INFLUENCIA DA EMBALAGEM DE POLIETILENO NA REMOÇÃO DA ADSTRINGÊNCIA E NA QUALIDADE DE CAQUIS (Diospyrus kaki L.), CV. GIOMBO, ARMAZENADOS SOB REFRIGERAÇÃO'
}

\author{
LUCIMARA ROGÉRIA ANTONIOLLI ${ }^{2}$, PAULO ROBERTO DE CAMARGO E CASTRO ${ }^{3}$, RICARDO \\ ALFREDO KLUGE ${ }^{4}$, JOÃO ALEXIO SCARPARE FILHO 5
}

\begin{abstract}
RESUMO - Verificou-se a influência da utilização de embalagem de polietileno, durante o armazenamento refrigerado, sobre o processo de remoção da adstringência de frutos de caquizeiro (Diospyros kaki L.), bem como sobre a qualidade dos frutos. Caquis 'Giombo' foram mantidos em câmara refrigerada a $1{ }^{\circ} \mathrm{C}$ e $95-98 \%$ UR, embalados ou não em polietileno de baixa densidade. Após 30 dias de armazenamento, os frutos foram submetidos ao processo de remoção da adstringência, mediante a exposição ao vapor de álcool etílico durante 40 horas a $20^{\circ} \mathrm{C}$ e $95 \%$ UR. As características químicas e físicas dos frutos foram avaliadas durante 6 dias. A utilização de embalagem de polietileno proporcionou menor perda de matéria fresca após o processo de destanização, não interferindo sobre o teor de taninos solúveis, firmeza de polpa, SST, ATT e teor de ácido ascórbico. Frutos armazenados por 30 dias e submetidos ao vapor de álcool etílico tornaram-se não adstringentes após 3 dias do tratamento; no entanto, apresentou baixa firmeza de polpa e elevada perda de matéria fresca.
\end{abstract}

Termos para indexação: Diospyros kaki, polietileno, tanino, álcool etílico.

\section{INFLUENCE OF POLYETHYLENE BAGS ON ASTRINGENCY REMOVAL AND QUALITY OF PERSIMMONS FRUITS (Diospyrus kaki L.), CV. GIONBO, STORED UNDER COLD CONDITIONS}

\begin{abstract}
The purpose of this research was to verify the influence of polyethylene bags during the cold storage of persimmon fruits (Diospyros kaki L.) when astringency removal is performed and to evaluate the quality of fruits when submitted to this process. Packed 'Gionbo' persimmons in low-density polyethylene bags and non-packed fruits were kept in a cold room at $1{ }^{\circ} \mathrm{C}$ and $95-98 \% \mathrm{RH}$. After 30 days of storage, fruits were submitted to astringency removal process by exposition to alcohol vapor for 40 hours at $20^{\circ} \mathrm{C}$ and $95 \%$ RH. Chemical and physical characteristics of the fruits were measured during 6 days. The use of polyethylene bags resulted in less fresh matter loss after the deastringency process, but it did not affected the soluble tannin content, flesh firmness, soluble solids, titratable acidity and ascorbic acid content. Fruits in storage for 30 days and submitted at ethyl alcohol vapor became non-astringent 3 days after the treatment. However they showed low flesh firmness and high fresh matter.
\end{abstract}

Index terms: Diospyros kaki, polyethylene, tannin, ethyl alcohol.

\section{INTRODUÇÃO}

A cultura do caquizeiro (Diospyros kaki L.) possui elevada importância econômica no Brasil, estando estabelecida nas regiões Sul e Sudeste, onde ocorrem condições climáticas favoráveis ao seu desenvolvimento (Brackmann \& Saquet, 1995).

A cultivar Giombo é classificada por Ito (1971), como pertencente ao tipo PCA; no entanto, Martins \& Pereira (1989) classificam essa cultivar como pertencente ao tipo variável, apresentando frutos com polpa bastante taninosa quando partenocárpicos e sem adstringência quando com sementes.

$\mathrm{O}$ armazenamento refrigerado destaca-se como uma possibilidade no prolongamento da vida pós-colheita dos frutos, refletindo na dilatação do período de comercialização. De maneira geral, os caquis são mais bem conservados sob condições de $90-100 \%$ de umidade relativa e temperatura de $1{ }^{\circ} \mathrm{C}$ (Ito, 1971 ; Lyon et al., 1992).

A utilização de embalagens de polietileno, visando à conservação dos frutos, promove uma modificação na atmosfera ao redor destes, devido à respiração do produto, que eleva a concentração de $\mathrm{CO}_{2}$ e diminui a concentração de $\mathrm{O}_{2}$ (Pesis et al., 1986).

Frutos de caquizeiro 'Giombo', acondicionados em sacos de polietileno com espessura de $0,08 \mathrm{~mm}$ e mantidos à temperatura de $0^{\circ} \mathrm{C}$, foram conservados durante dois meses, enquanto os frutos mantidos sob atmosfera normal a $0^{\circ} \mathrm{C} \mathrm{e} 90 \%$

\footnotetext{
1 Trabalho ${ }^{\circ}$ 180/2000. Recebido: 17/08/2000. Aceito para publicação: 14/04/2001. Parte da Dissertação de Mestrado do primeiro autor apresentada à ESALQ/USP. Apoio: CAPES.

2 Enga. Agr ${ }^{\mathrm{a}}$., M. Sc., Dep. Pré-Processamento de Produtos Agropecuários, FEAGRI/UNICAMP, Caixa Postal 6011, CEP 13083-970. Campinas, SP.E-mail: 1rantoni@agr.unicamp.br

3 Eng $^{\circ}$. Agr ${ }^{\circ}$, Dr., Prof., Dep. Ciências Biológicas, ESALQ/USP. E-mail: prccastr@carpa.ciagri.usp.br

4 Eng $^{\circ}$. Agro., Dr., Prof., Dep. Ciências Biológicas, ESALQ/USP. E-mail: rakluge@carpa.ciagri.usp.br

5 Eng ${ }^{\circ}$. Agr ${ }^{\circ}$., Dr., Prof., Dep. Produção Vegetal, ESALQ/USP. E-mail: jascarpa@carpa.ciagri.usp.br
} 
UR foram conservados somente durante seis semanas (Martins \& Pereira, 1989). Pekmezci et al. (1997) relataram um experimento em que frutos de caquizeiro 'Fuyu' puderam ser armazenados até seis meses a $0^{\circ} \mathrm{C}$ quando acondicionados, individualmente, em embalagem de polietileno com espessura de $0,06 \mathrm{~mm}$.

Vidrih et al. (1994) citaram que frutos de caquizeiro mantidos sob atmosfera com alta concentração de $\mathrm{CO}_{2}$ acumulam elevadas concentrações de etanol e acetaldeído, como resultado das modificações no processo respiratório. $\mathrm{O}$ acetaldeído pode reagir com os taninos solúveis, causando sua polimerização e tornando-os insolúveis (Ito, 1971). No entanto, Moura et al. (1997) indicaram a necessidade de indução ao amadurecimento de frutos de caquizeiro 'Taubaté', que mantiveram o teor de tanino e o grau de adstringência constante, durante o período de 72 dias a $0 \cdot \mathrm{C}$, mesmo com a utilização de embalagem.

Vários são os produtos possíveis de serem utilizados na remoção da adstringência do caqui, como álcool, vinagre, água de cal, etileno e carbureto de cálcio (Penteado, 1986). Tais tratamentos estimulam o acúmulo de compostos voláteis na polpa dos frutos, como etanol e acetaldeído, e estas substâncias, especialmente o acetaldeído, induzem os taninos solúveis a se polimerizarem e formarem complexos insolúveis, resultando, com isso, na perda da adstringência (Sugiura \& Tomana, 1983).

Frutos de caquizeiro 'Okira' tratados com álcool apresentaram resistência de polpa superior aos frutos tratados com vinagre e ethephon, após o processo de destanização (Biasi \& Gerhardt, 1992). Este resultado confirmou as observações de Martins \& Pereira (1989), que citaram o álcool como um agente destanizador que possibilitou a obtenção de frutos com polpa firme após o processo. De acordo com Pesis et al. (1986), caquis com valor de firmeza inferior a $5,0 \mathrm{~kg} . \mathrm{cm}^{-2}$ são considerados moles.

O tratamento com etanol, quando realizado sob temperaturas de 15 ou $20^{\circ} \mathrm{C}$, possibilitou a manutenção da qualidade de caquis 'Aizumishirazu' e 'Hiratanenashi' por mais de dez dias (Kato, 1987).

A carência de trabalhos relacionados aos efeitos do armazenamento refrigerado e da atmosfera modificada no processo de remoção da adstringência objetivou a realização deste trabalho, onde se procurou verificar a influência da utilização de embalagem de polietileno durante 30 dias de armazenamento refrigerado sobre o processo de remoção da adstringência, mediante a exposição dos frutos ao vapor de álcool etílico, bem como avaliar a qualidade dos frutos submetidos a este processo.

\section{MATERIAL E MÉTODOS}

Caquis 'Giombo' foram colhidos no mês de maio de 1998, em pomar comercial localizado no município de GuapiaraSP, situado a $24^{\circ} 11^{\prime}$ de latitude Sul e $48^{\circ} 02^{\prime}$ de longitude Oeste e a 900 metros de altitude, com clima do tipo Cfb, segundo Köppen.

Os frutos utilizados apresentavam coloração $100 \%$ alaranjada e bastante uniforme. Após a colheita, foram transportados ao Laboratório de Fisiologia Pós-Colheita do Departamento de Ciências Biológicas da Escola Superior de Agricultura "Luiz de Queiroz", onde se realizou rigorosa seleção quanto ao tamanho e qualidade.

Os frutos foram embalados em sacos de polietileno de baixa densidade com espessura de $0,06 \mathrm{~mm}$ e armazenados a $1 \pm$ $0,5^{\circ} \mathrm{C}$ e $95-98 \%$ UR durante 30 dias. Frutos sem embalagem foram considerados controle.

Após o armazenamento, os frutos foram destanizados mediante a exposição ao vapor de álcool etílico, durante 40 horas à temperatura de $20^{\circ} \mathrm{C}$. Utilizou-se álcool etílico hidratado $92,8^{\circ}$ INPM (álcool comercial) na proporção de $3,85 \mathrm{~mL} . \mathrm{L}^{-1}$ câmara $\left(3,85 \mathrm{~L} \cdot \mathrm{m}^{-3}\right)$.

Terminado o processo, os frutos foram mantidos sob temperatura ambiente $\left(24-25^{\circ} \mathrm{C}\right)$.

As características químicas e físicas dos frutos foram avaliadas em três ocasiões: imediatamente após a retirada da câmara refrigerada e 3 e 6 dias após o processo de remoção da adstringência.

As variáveis analisadas foram: a) teor de taninos solúveis (g. $\left.100 \mathrm{~g}^{-1} \mathrm{polpa}\right)$ : determinado espectrofotometricamente utilizando-se o reagente de Follin-Denis, segundo técnica recomendada por Carvalho et al. (1990), onde uma amostra de 5g de polpa triturada e homogeneizada foi diluída para um volume final de $100 \mathrm{~mL}$ com água destilada do qual se retirou uma alíquota de $5 \mathrm{~mL}$. A esta alíquota adicionaram-se reagente de Follin-Denis e solução de carbonato de sódio, completando o volume a $100 \mathrm{~mL}$ com água destilada. Após 30 minutos, a solução foi filtrada e, em seguida, determinou-se a absorbância a $760 \mathrm{~nm}$. Foi utilizada, como padrão, uma solução de ácido tânico $\left(0,1 \mathrm{~g} \cdot \mathrm{L}^{-1}\right)$; b) firmeza de polpa $\left(\mathrm{kg} . \mathrm{cm}^{-2}\right)$ : medida com penetrômetro EFFE-GI, com ponteira de $6,5 \mathrm{~mm}$ de diâmetro, efetuando-se duas leituras em lados opostos na região equatorial dos frutos, após a remoção de uma pequena área da casca. Associou-se o início do amolecimento da polpa ao valor de firmeza de $5 \mathrm{~kg}_{\mathrm{cm}} \mathrm{cm}^{-2}$, conforme preconizado por Pesis et al. (1986); c) perda de matéria fresca (\%): avaliada durante o armazenamento em câmara refrigerada e calculada pela diferença entre as massas inicial e final, sendo apresentada como porcentagem da massa inicial, avaliada durante o período de exposição ao vapor de álcool etílico e durante 6 dias após o tratamento; d) sólidos solúveis totais ( ${ }^{\circ}$ Brix): determinado por refratometria, com correção de temperatura para $20^{\circ} \mathrm{C}$; e) acidez total titulável (\% ácido málico): determinada através da diluição de $10 \mathrm{~mL}$ da amostra em $90 \mathrm{~mL}$ de água destilada, e posterior titulação com solução de $\mathrm{NaOH} 0,1 \mathrm{~N}$, até $\mathrm{pH}$ de 8,$10 ;$ f) teor de ácido ascórbico (mg ácido ascórbico.100 $\mathrm{g}^{-1}$ polpa): determinado segundo metodologia de Carvalho et al. (1990), a qual se baseia na redução do indicador 2,6diclorobenzenoindofenol (DCFI) pelo ácido ascórbico.

O delineamento experimental adotado foi o inteiramente casualizado, em esquema fatorial $2 \times 2$. Os fatores estudados foram: embalagem de polietileno durante $\mathrm{o}$ armazenamento (com e sem) e períodos de avaliação (3 e 6 dias). A cada avaliação, foram utilizadas quatro repetições com cinco frutos por parcela.

Os dados coletados foram submetidos à análise de variância e as médias comparadas pelo teste de Tukey, ao nível de $5 \%$ de probabilidade.

\section{RESULTADOS E DISCUSSÃO}

A utilização de embalagem de polietileno, durante o armazenamento refrigerado, reduziu o teor de taninos solúveis dos frutos em cerca de $50 \%$, quando comparado ao tratamento 
TABELA 1 - Efeito da utilização de embalagem de polietileno sobre as características físico-químicas de caquis ‘Giombo' avaliadas imediatamente após o armazenamento refrigerado. ESALQ, Piracicaba-SP, 19981.

Características
Armazenamento refrigerado

Com embalagem

0,24

9,21

0,07

18,27

0,1027

46,50
Sem embalagem

0,45

9,99

2,98

20,40

0,1161

43,89

ATT (\% ácido málico)
Ácido ascórbico (mg. $\left.100 \mathrm{~g}^{-1}\right)$

${ }^{1}$ Valores médios

TABELA 2 - Efeito da utilização de embalagem de polietileno durante o armazenamento refrigerado sobre as características físicoquímicas avaliadas após o processo de remoção da adstringência de caquis 'Giombo'. ESALQ, Piracicaba-SP, 1998.

\begin{tabular}{|c|c|c|c|}
\hline \multirow{2}{*}{$\begin{array}{l}\text { Armazenamento } \\
\text { refrigerado }\end{array}$} & \multicolumn{2}{|c|}{ Dias após a destanização } & \multirow[t]{2}{*}{ Média } \\
\hline & 3 & 6 & \\
\hline & \multicolumn{2}{|c|}{----- Taninos solúveis $\left(\mathrm{g} .100 \mathrm{~g}^{-1}\right)$----- } & \multirow[b]{2}{*}{$0,08 \mathrm{a}$} \\
\hline Com embalagem & 0,11 & 0,05 & \\
\hline Sem embalagem & 0,06 & 0,05 & $0,06 \mathrm{a}$ \\
\hline Média & $0,08 \mathrm{~A}$ & $0,05 \mathrm{~A}$ & - \\
\hline \multicolumn{4}{|c|}{---- Firmeza $\left(\mathrm{kg} . \mathrm{cm}^{-2}\right)$--- } \\
\hline Com embalagem & 3,28 & 1,62 & $2,38 \mathrm{a}$ \\
\hline Sem embalagem & 2,59 & 2,76 & $2,67 \mathrm{a}$ \\
\hline Média & $2,92 \mathrm{~A}$ & $2,15 \mathrm{~A}$ & - \\
\hline \multicolumn{4}{|c|}{---- Perda de matéria fresca $(\%)$---- } \\
\hline Com embalagem & 1,93 & 3,85 & $2,89 \mathrm{~b}$ \\
\hline Sem embalagem & 2,25 & 4,11 & $3,18 \mathrm{a}$ \\
\hline Média & $2,09 \mathrm{~B}$ & $3,98 \mathrm{~A}$ & - \\
\hline \multicolumn{4}{|c|}{----------- SST ('Brix) ------------ } \\
\hline Com embalagem & 20,54 & 21,38 & $20,91 \mathrm{a}$ \\
\hline Sem embalagem & 21,17 & 21,01 & $21,09 \mathrm{a}$ \\
\hline Média & $20,85 \mathrm{~A}$ & $21,15 \mathrm{~A}$ & - \\
\hline \multicolumn{4}{|c|}{------- ATT (\% ácido málico) ------- } \\
\hline Com embalagem & 0,1064 & 0,0708 & $0,0879 \mathrm{a}$ \\
\hline Sem embalagem & 0,0681 & 0,0599 & $0,0639 \mathrm{a}$ \\
\hline Média & $0,0864 \mathrm{~A}$ & $0,0652 \mathrm{~A}$ & - \\
\hline \multicolumn{4}{|c|}{---- Ácido ascórbico (mg.100g $\mathrm{g}^{-1}$ )---- } \\
\hline Com embalagem & 34,55 & 42,49 & $38,52 \mathrm{a}$ \\
\hline Sem embalagem & 31,72 & 39,53 & 35,63 a \\
\hline Média & $33,14 \mathrm{~B}$ & $41,01 \mathrm{~A}$ & - \\
\hline
\end{tabular}

Para cada variável, as médias seguidas pela mesma letra minúscula na coluna e maiúscula na linha não diferem significativamente entre si, pelo teste de Tukey, ao nível de 5\% de probabilidade. 


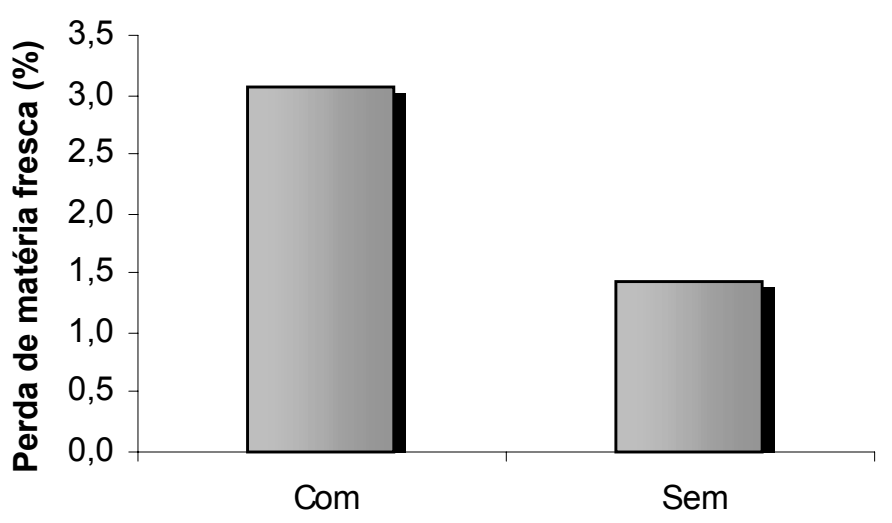

Embalagem durante 0 armazenamento

FIGURA 1 - Perda de matéria fresca de frutos de caquizeiro 'Giombo' durante a exposição ao vapor de álcool etílico. (As letras minúsculas indicam diferença significativa ao nível de 5\% de probabilidade, pelo teste de Tukey). ESALQ, Piracicaba-SP, 1998.

sem embalagem (Tabela 1). Esse resultado pode ser explicado pelo fato de que a atmosfera modificada, gerada pela embalagem, reduziu os níveis de $\mathrm{O}_{2}$ e aumentou os de $\mathrm{CO}_{2}$ ao redor dos frutos, o que proporcionou condições favoráveis a insolubilização dos taninos. Altas concentrações de $\mathrm{CO}_{2}$ e baixas de $\mathrm{O}_{2}$ promovem o acúmulo de etanol e acetaldeído, como resultado de modificações no processo respiratório (Pesis et al., 1986; Vidrih et al., 1994). Essas substâncias reagem com os taninos solúveis tornando-os insolúveis (Ito, 1971). Embora o teor de taninos solúveis dos frutos armazenados sem embalagem, verificado ao término do armazenamento, tenha sido bastante superior ao dos frutos armazenados com embalagem $(0,45 \mathrm{e}$ $0,24 \mathrm{~g} .100 \mathrm{~g}^{-1}$, respectivamente), verificou-se que, durante a destanização, os frutos provenientes de ambos os tratamentos atingiram teores muito próximos, que não diferiram estatisticamente entre si (Tabela 2). Aos três dias após o tratamento para destanização, os frutos apresentaram baixos teores de taninos solúveis $\left(0,1 \mathrm{~g} .100 \mathrm{~g}^{-1}\right.$, em média), teor este não detectável ao paladar, segundo Vidrih et al. (1994).

A firmeza de polpa apresentou drástica diminuição após o tratamento de remoção da adstringência (Tabelas 1 e 2), não havendo influência do uso da embalagem. Esta ausência de resposta da utilização de embalagem plástica foi semelhantemente verificada por Moura (1995). Os frutos apresentaram-se excessivamente amolecidos ao terceiro dia após a destanização, tornando-se inadequados à comercialização, considerando-se que os frutos desta cultivar são consumidos firmes. No presente experimento, os resultados de firmeza podem ter sido influenciados pelo estádio de maturação dos frutos, considerando que a colheita foi tardia (final de safra), o que pode ter acelerado a senescência dos frutos.

A embalagem de polietileno reduziu em $98 \%$ a perda de matéria fresca durante o armazenamento refrigerado, em comparação ao tratamento sem embalagem (Tabela 1).

Verifica-se, na Figura 1, que durante a exposição ao vapor de álcool etílico, os frutos anteriormente armazenados com embalagem apresentaram uma perda de matéria fresca estatisticamente superior aos frutos armazenados sem embalagem, o que pode ser explicado pela diferença no "déficit" de pressão de vapor (DPV) estabelecido nos dois ambientes de armazenamento. A alta umidade relativa no interior da embalagem reduziu o DPV e, conseqüentemente, a perda de matéria fresca dos frutos durante o armazenamento (Pesis et al., 1986). No entanto, ao se retirar os frutos da embalagem, a diferença entre a pressão de vapor dos espaços intercelulares do fruto e do ar circundante, menos saturado, tornou-se mais acentuada, conduzindo à maior perda de matéria fresca através da transpiração. Os frutos armazenados sem embalagem não sofreram mudança acentuada de DPV, uma vez que a umidade relativa no interior da câmara de armazenamento estava próxima à umidade relativa da câmara de destanização.

Durante a avaliação, a perda de matéria fresca foi estatisticamente superior nos frutos armazenados sem embalagem (Tabela 2). Verificou-se aumento na perda de matéria fresca em função do tempo, atingindo o valor médio de 3,98\% ao final do sexto dia de avaliação (Tabela 2). Observou-se que os frutos apresentaram perda de matéria fresca acumulada, equivalente à perda durante 30 dias de armazenamento e às perdas durante o tratamento de destanização e avaliação; sendo que os frutos armazenados com embalagem apresentaram perda de matéria fresca equivalente a $6,03 \%(0,07 ; 3,07$ e 2,89\%, respectivamente), enquanto os frutos armazenados sem embalagem perderam $7,59 \%$ de matéria fresca $(2,98 ; 1,43$ e 3,18\%, respectivamente). Verificou-se, dessa forma, que a utilização de embalagem durante o armazenamento refrigerado proporcionou menor perda de matéria fresca ao final do processo.

Quanto ao teor de sólidos solúveis totais (SST), verificou-se que os frutos não embalados apresentaram maiores valores do que os embalados logo após o armazenamento refrigerado (20,40 e $18,27^{\circ} \mathrm{Brix}$, respectivamente) (Tabela 1). Isso pode ser decorrente da maior perda de matéria fresca observada nos frutos não embalados durante o armazenamento, o que fez com que a concentração de açúcares se elevasse. Após a destanização, não foi verificada diferença para o teor de SST (Tabela 2).

A acidez total titulável (ATT) não foi influenciada pelos tratamentos (Tabela 2). O teor de ácido ascórbico, principal componente da vitamina $\mathrm{C}$, não foi influenciado pela utilização de embalagem durante o armazenamento refrigerado; no entanto, houve diferença significativa entre 3 e 6 dias posteriores à exposição dos frutos ao vapor de álcool etílico (Tabela 2). O aumento verificado no teor de ácido ascórbico, possivelmente, justifica-se pelo fato de o método empregado ser destrutivo, de forma que os frutos comparados podem apresentar teores iniciais diferenciados.

\section{CONCLUSÕES}

1 - A utilização de embalagem de polietileno durante 30 dias de armazenamento refrigerado proporciona menor perda de matéria fresca, não interferindo no teor de taninos solúveis, firmeza de polpa, sólidos solúveis totais, acidez total titulável e teor de ácido ascórbico dos frutos após o processo de remoção da adstringência.

2 - O armazenamento refrigerado dos frutos pode ser realizado durante 30 dias sob temperatura de $1^{\circ} \mathrm{C}$ e $95-98 \%$ UR; no entanto, os frutos apresentam baixa firmeza de polpa e elevada perda de matéria fresca após o processo de destanização. 


\section{REFERÊNCIAS BIBLIOGRÁFICAS}

BIASI, L.A.; GERHARDT, I.R. Efeito da aplicação de vinagre, álcool e ethephon na destanização de caquis cv. Okira. Revista Brasileira de Fruticultura, Cruz das Almas, v.14, n.2, p.31-36, 1992.

BRACKMANN, A.; SAQUET, A.A. Efeito da temperatura e condições de atmosfera controlada sobre a conservação de caqui (Diospyros kaki L.). Ciência Rural, Santa Maria, v.5, n.3, p.375378, 1995.

CARVALHO, C.R.L.; MANTOVANI, D.M.B.; CARVALHO, P.R.N.; MORAES, R.M.M. Análises químicas de alimentos. Campinas: ITAL, 1990. 121p. (Manual Técnico).

ITO, S. The persimmon. In: HULME, A.C. The biochemistry of fruits and their products. London: Academic Press, 1971, v.2, cap. 8, p.281-301.

KATO, K. Astringency removal and ripening as related to temperature during the astringency removal by ethanol in persimmon fruits. Journal of the Japanese Society for Horticultural Science, Kyoto, v.55, n.4, p.498-509, 1987.

LYON, B.G.; SENTER, S.D.; PAYNE, J.A. Quality characteristics of oriental persimmons (Diospyros kaki L. cv. Fuyu) grown in the southeastern United States. Journal of Food Science, Champaign, v.57, n.3, p.693-695, 1992.

MARTINS, F.P.; PEREIRA, F.M. Cultura do caquizeiro. Jaboticabal: FUNEP, 1989. 71p.
MOURA, M.A. Efeito da embalagem e do armazenamento no amadurecimento do caqui (Diospyros kaki L.) cultivar Taubaté. 1995. 84f. Dissertação (M.S.) - Universidade Federal de Viçosa, Viçosa, 1995.

MOURA, M.A.; LOPES, L.C.; CARDOSO, A.A.; MIRANDA, L.C.G. Efeito da embalagem e do armazenamento no amadurecimento do caqui. Pesquisa Agropecuária Brasileira, Brasília, v.32,n.11, p.1105-1109, 1997.

PEKMEZCI, M.; ERKAN, M.; GÜBBÜK, H. The effects of harvest time, and method and duration of storage on quality of 'Hachiya' e 'Fuyu' persimmons. Acta Horticulturae, Wageningen, n.441, p.279-286, 1997.

PENTEADO, S.R. Cultura do caquizeiro. In: PENTEADO, S.R. Fruticultura de clima temperado em São Paulo. Campinas: Fundação Cargill, 1986. cap.8, p.157-173.

PESIS, E.; LEVI, A.; BEN-ARIE, R. Deastringency of persimmon fruits by creating a modified atmosphere in polyethylene bags. Journal of Food Science, Champaign, v.51, n.4, p.1014-1016, 1041, 1986.

SUGIURA, A.; TOMANA, T. Relationships of ethanol production by seeds of different types of Japanese persimmons and their tannin content. HortScience, Alexandria, v.18, n.3, p.319-321, 1983.

VIDRIH, R.; SIMCIC, M.; HRIBAR, J.; PLESTENJAK, A. Astringency removal by high $\mathrm{CO}_{2}$ treatment in persimmon fruit (Diospyros kaki). Acta Horticulturae, Wageningen, n.368, p.652656, 1994. 